\title{
LETTERS \\ Change in Medical Student Implicit Bias
}

\author{
John M. Westfall, MD, MPH \\ University of Colorado School of Medicine, Aurora, CO, USA.
}

J Gen Intern Med 31(7):714

DOI: $10.1007 / \mathrm{s} 11606-016-3684-4$

(C) Society of General Internal Medicine 2016

$\mathrm{D}$ ear Editor,

The paper by van Ryn et al. describes a courageous study aimed at documenting and improving racial bias among medical students and, ultimately, practicing physicians. ${ }^{1}$ I am struck by the significant racial bias against African Americans reported in the study and the apparent worse racial bias found at the end of medical school compared to the start. Several findings deserve further description and discussion. The main outcome was change in implicit racial attitudes between the first and last semesters of medical school. This overall outcome is not included in the manuscript. What is the mean Implicit Association Test (IAT) score in year 1 compared to the overall mean score in year 4 ? How do medical students compare to the rest of the nation, or other students, or those aged 20-30? Medical school may inadvertently teach implicit bias. Of course, medical schools do not intend to teach racial bias. However, medical education of differential diagnosis teaches pattern recognition and to begin making and honing a diagnosis upon first impression and introduction to a patient. ${ }^{2,3}$ The ultimate goal in differential diagnosis is that of the automatic "augenblick" diagnosis; making the diagnosis in the "blink of an eye." Is this an automatic implicit bias diagnosis? Our pedagogy may be undermining our efforts to reduce implicit bias and improve care for diverse patient populations. Nearly half of the students reported hearing negative comments about black patients from resident or attending physicians. The unintended consequence of teaching good differential diagnosis mixed with the inappropriate stereotypes offered in media and through derogatory comments made by faculty, staff, and other students may be increasing implicit racial bias among medical students. While it is encouraging that formal curricula reduce racial bias, the negative impact reported for informal curricula and interracial contact appear to overwhelm this benefit. My guess is that these two domains are not causative, just associated with the general increase in implicit bias from our educational process. Of course, there should be zero tolerance for negative comments about black patients. Improving attitudes and decreasing racial bias may also require attention to the underlying teaching of differential diagnosis and explicit conversations about the benefits and risks of the augenblick.

Corresponding Author: John M. Westfall, MD, MPH; University of Colorado School of Medicine, Aurora, CO, USA (e-mail: jack.westfall@ucdenver.edu).

\section{REFERENCES}

1. Van Ryn M, Hardeman R, Phelan SM, Burgess DJ, Dovidio JF, Herrin J, Burke SE, Nelson DB, Perry S, Yeazel M, Przedworski JM. Medical School Experiences Associated with Change in Implicit Racial Bias Among 3547 Students: A Medical Students CHANGES Study Report. J Gen Intern Med. 2015;30(12):1748-56. doi:10.1007/s11606-015-3447-7.

2. Eddy DM, Clanton CH. The Art of Diagnosis - Solving the Clinicopathological Exercise. N Engl J Med. 1982;306:1263-8.

3. Siegenthaler W. Differential Diagnosis in Internal Medicine: From Symptom to Diagnosis. New York, NY. Thieme Publishers, 2007. ISBN-13 978-1-58890551-2.

4. Campbell ww. Augenblickdiagnose. Semin Neurol. 1998;18(2):169-76. doi: 10.1055/s-2008-1040870. 